\title{
Rice millers' syndrome: a preliminary report
}

\author{
H H LIM,${ }^{1}$ Z DOMALA, ${ }^{1}$ S JOGINDER,${ }^{2}$ S H LEE $,{ }^{3} \mathrm{C} S \mathrm{LIM},{ }^{3}$ AND C M ABU BAKAR ${ }^{4}$ \\ From the Departments of Social and Preventive Medicine ${ }^{1}$ and Radiology, ${ }^{2}$ Faculty of Medicine, University of \\ Malaya, the Department of Environmental Sciences, ${ }^{3}$ Agriculture University of Malaysia, and the Factories \\ and Machinery Department, ${ }^{4}$ Ministry of Labour and Manpower, Kuala Lumpur, Malaysia
}

\begin{abstract}
A study was carried out to determine the health effects of rice husk dust in Malaysian rice millers. The study population consisted of 122 male Malay workers from three rice mills, with 42 controls of similar age, sex, ethnic group, and agricultural work background. Interviews using standardised questionnaires, physical examination, total and differential white cell counts, chest radiographs, and lung function tests were performed on each of the millers and the controls. Environmental dust monitoring was also carried out in the three rice mills. Clinical, haematological, and radiological findings suggest that a distinct clinical syndrome seems to be associated with exposure to rice husk dust. The manifestations of this "rice millers' syndrome" include acute and chronic irritant effects affecting the eyes, skin, and upper respiratory tract; allergic responses such as nasal catarrh, tightness of chest, asthma, and eosinophilia; and radiological opacities in the chest, probably representing early silicosis or extrinsic allergic alveolitis.
\end{abstract}

In many Asian countries rice is a major agricultural crop and forms the staple food of more than one quarter of the world's population. The cultivation of rice (Oryza sp) is usually carried out in irrigated "padi" (fields). After harvesting, the rice is dried and milled and a large amount of dust is thereby generated. Apart from reported cases of occupational asthma ${ }^{1}$ and keratitis nummularis, ${ }^{2}$ little research has been carried out on the effects of rice husk dust. A study was thus carried out in Malaysia (a major rice growing country) to determine whether there were adverse health effects associated with occupational exposure to rice husk dust.

\section{Methods}

The study population consisted of all workers employed at the time of the study (March-May 1983) in three rice mills in the rice growing area of the State of Selangor. Altogether there were 122 male Malay subjects. As controls, 42 workers employed as farmers in an agricultural work station in the same state were selected. The controls were of the same sex and ethnic group and from a similar agricultural work background but without exposure to rice husk dust.
Each subject and control was interviewed by a physician using a standard questionnaire based on the British Medical Research Council questionnaire on respiratory symptoms. This also contained questions pertaining to symptoms of eye irritation (defined as any complaints of itchiness, grittiness, soreness, lachrymation, redness, or photophobia of the eyes) and pruritus (defined as any complaints of itchiness or irritation of the skin with or without rashes). A full physical examination was also carried out on each subject and control by another physician who was not aware of the dust exposure levels. Blood samples were also collected by finger prick using a triangular surgical needle and analysed for total white and differential count by a trained laboratory technologist. For total white count, $2 \%$ aqueous acetic acid solution was used for dilution and counting was carried out using an improved Neubauer chamber. Leishman's stain was used for slide preparation in the differential white count.

Standard erect posterior anterior chest radiographs were taken for each subject and control, using conventional exposure of between $60-80 \mathrm{KV}$ without an absorption grid. The focal film distance was fixed at three metres, with centering point between fourth or fifth thoracic vertebra. Exposures were obtained at full suspended inspiration with elbows flexed, back of hands placed on hips, and elbows pushed gently forwards. Exposure time was between 0.05 and 0.08 seconds. The radiographs 445 
Table 1 Age distribution of rice mill workers and controls

\begin{tabular}{lcc}
\hline Age (years) & Rice millers & Controls \\
\hline $16-19$ & 11 & 2 \\
$20-24$ & 33 & 13 \\
$25-29$ & 21 & 8 \\
$30-34$ & 22 & 15 \\
$35-39$ & 14 & 3 \\
$40-44$ & 5 & 1 \\
$45-49$ & 9 & 0 \\
$\geqslant 50$ & 7 & 0 \\
Total & 122 & 42 \\
Mean & $30 \cdot 6^{*}$ & $27 \cdot 6^{*}$ \\
SD & $10 \cdot 0$ & $5 \cdot 6$ \\
\hline
\end{tabular}

*No significant difference, $t=1 \cdot 86, p>0.05$.

were read by a radiologist and the examining physician who were not aware of the subjects' dust exposure levels. Findings were classified into broad descriptive categories (such as nodular opacities, increased reticulation, generalised haze, and fibrotic opacities of old tuberculosis) without any attempt being made at this stage to use the ILO International Classification.

Ventilatory function, forced expiratory volume in one second $\left(\mathrm{FEV}_{1}\right)$ and forced vital capacity (FVC) were measured in each subject and control using a Vitalograph spirometer, the instrument being calibrated before conducting the investigation. Measurements were made on the first working day of the week, at the beginning and end of the work shift. The subjects were tested in a standing position with the chin slightly raised and the neck slightly extended. At least three forced expirations were made, with the average of three acceptable measurements being taken. All measurements were corrected to body temperature, ambient pressure, and saturated water vapour (BTPS).

Environmental monitoring was carried out using a high volume sampler (flow rate 1.13 to $1.70 \mathrm{cu} \mathrm{m} /$ min) to determine the total dust levels in all the various work sections of the rice mills. Personal monitoring was carried out using MSA portable pumps, fitted with Millipore PVC membrane filters $(0.5 \mu \mathrm{m}$ pore size, $37 \mathrm{~mm}$ diameter) in three piece cassettes, using a cyclone unit (flow rate $2 \cdot 0 \mathrm{l} / \mathrm{min}$ ). Three to five workers from each of the various work sections were randomly selected for monitoring.

Table 2 Smoking habits of rice millers and controls

\begin{tabular}{lrrrrr}
\hline & \multicolumn{2}{l}{ Rice millers } & & \multicolumn{2}{l}{ Controls } \\
\cline { 2 - 3 } \cline { 5 - 6 } \cline { 5 - 6 } & No & $\%$ & & No & $\%$ \\
\hline Smokers & 68 & $55 \cdot 7$ & & 26 & 61.9 \\
Ex-smokers & 13 & 10.7 & & 2 & $4 \cdot 8$ \\
Non-smokers & 41 & 33.6 & & 14 & 33.3 \\
Total & 122 & 100.0 & 42 & 100.0 \\
\hline
\end{tabular}

No significant difference, $\chi^{2}=1 \cdot 39, p>0.05$.
Table 3 Positive clinical symptoms present in rice millers and controls

\begin{tabular}{|c|c|c|c|c|}
\hline \multirow[t]{2}{*}{ Symptom or symptom complex } & \multicolumn{2}{|c|}{ Rice millers } & \multicolumn{2}{|c|}{ Controls } \\
\hline & No & $\%$ & No & $\%$ \\
\hline $\begin{array}{l}\text { Irritant cough with phlegm } \\
\text { Irritant cough without phlegm } \\
\text { Eye irritation } \\
\text { Nasal catarrh } \\
\text { Pruritus } \\
\text { Rashes } \\
\text { Tightness of chest }\end{array}$ & $\begin{array}{l}51 \\
26 \\
80 \\
59 \\
80 \\
36 \\
32\end{array}$ & $\begin{array}{l}41 \cdot 8^{*} \\
21 \cdot 3^{*} \\
65 \cdot 6^{*} \\
48 \cdot 4^{*} \\
65 \cdot 6^{*} \\
29 \cdot 5^{*} \\
26 \cdot 2^{*}\end{array}$ & $\begin{array}{r}1 \\
2 \\
3 \\
0 \\
11 \\
11 \\
3\end{array}$ & $\begin{array}{r}2 \cdot 4^{*} \\
4 \cdot 8^{*} \\
7 \cdot 1^{*} \\
0 \cdot 0^{*} \\
26 \cdot 2^{*} \\
26 \cdot 2 \\
7 \cdot 1^{*}\end{array}$ \\
\hline $\begin{array}{l}\text { Tightness of chest on particular } \\
\text { day. }\end{array}$ & 1 & $0 \cdot 8$ & 0 & $0 \cdot 0$ \\
\hline $\begin{array}{l}\text { Chronic cough or phlegm } \\
\geqslant 2 \text { years } \\
\text { Periods of increased cough or }\end{array}$ & 8 & $6 \cdot 6$ & 0 & 0.0 \\
\hline $\begin{array}{l}\text { phlegm } \geqslant 3 \text { months } \\
\text { Chronic asthma (developing after }\end{array}$ & 17 & $13 \cdot 9$ & 3 & $7 \cdot 1$ \\
\hline $\begin{array}{l}\text { starting work) } \\
\text { Dyspnoea of grade } 2 \text { or higher }\end{array}$ & $\begin{array}{l}6 \\
6\end{array}$ & $\begin{array}{l}4.9 \\
4.9\end{array}$ & $\begin{array}{l}0 \\
2\end{array}$ & $\begin{array}{l}0 \cdot 0 \\
4 \cdot 8\end{array}$ \\
\hline
\end{tabular}

${ }^{*}$ Significant difference, $\mathrm{p}<0.05$.

\section{Results}

There was no significant difference between the mean age of the subjects $(30.6$ years) and the controls $(27.6$ years $),(t=1 \cdot 86, p>0.05)($ table 1$)$. The smoking habits of the workers and controls are compared in table 2 ; there was no significant difference $\left(\chi^{2}=1 \cdot 39, p>0.05\right)$.

Table 3 shows the clinical symptoms of which the rice millers and controls complained. A significantly greater proportion of the rice millers complained of irritant cough with or without phlegm, eye irritation, nasal catarrh, pruritus, and tightness of chest. A greater proportion of the rice millers (although not statistically significant at the 0.05 level) also complained of chronic cough or phlegm exceeding two years' duration, increased cough or phlegm lasting longer than three months within a one year period, and chronic asthmatic episodes that developed after starting work in the rice mills. Cases of asthma that started during childhood or before starting work were excluded from the analysis.

Table 4 shows the clinical signs detected in the

Table 4 Positive clinical and haematological signs in rice millers and controls

\begin{tabular}{lccllll}
\hline & \multicolumn{2}{l}{ Rice millers } & & \multicolumn{2}{l}{ Controls } \\
\cline { 2 - 3 } \cline { 5 - 6 } \cline { 5 - 6 } & No & $\%$ & & & No & $\%$ \\
\hline Clinical: & 39 & $32 \cdot 0^{*}$ & & & \\
Conjunctivitis & 30 & $24 \cdot 6^{*}$ & & 0 & $0 \cdot 0^{*}$ \\
Pterygium & 3 & $2 \cdot 5$ & & 1 & $2 \cdot 0^{*}$ \\
Corneal scar & 2 & $1 \cdot 6$ & & $4 \cdot 8$ \\
Dermatosis & 7 & $5 \cdot 7$ & & 1 & $2 \cdot 4$ \\
Rhonchi/crepitations & & & & & & \\
Haematological: & 27 & $22 \cdot 1^{*}$ & & 3 & $7 \cdot 1^{*}$ \\
Eosinophilia & & & & &
\end{tabular}

*Significant difference, $\mathrm{p}<0 \cdot 05$ : 


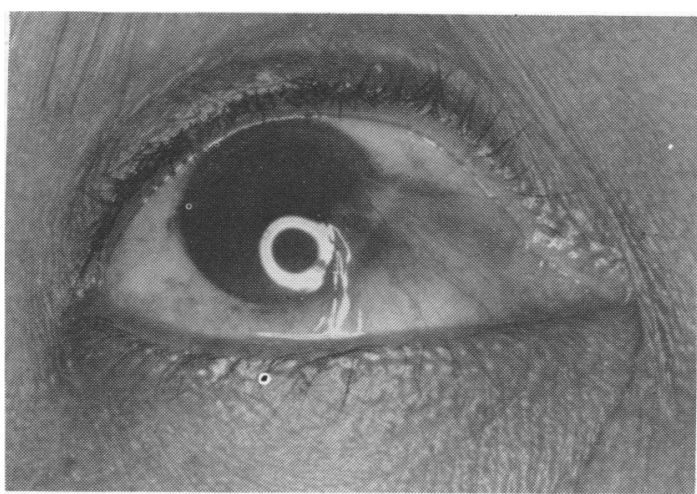

Fig 1 Photograph of right eye in a rice miller, showing conjunctival injection and a pterygium extending from medial angle of eye on to cornea. (Bright ring in centre is a reflection of camera lens.)

two groups. A significantly greater proportion of rice millers was found to have conjunctivitis, pterygium (fig 1), and eosinophilia. There were also three cases with corneal scars among the rice millers compared with one among the controls that had resulted from accidental trauma in childhood. Seven cases with chest signs suggestive of obstructive airway disease (decreased air entry and rhonchi) were detected among the rice millers compared with only one case among the controls.

The proportions of workers with chest abnormalities detected on radiological examination are given in table 5, from which it may be seen that a significantly greater proportion of rice millers $(14.8 \%)$ had chest opacities with or without increased reticulation. The opacities consisted mainly of fine nodulation in the lower and midzones of the lungs (figs 2 and 3) but one worker also had a large nodule measuring $11 / 2 \mathrm{~cm}$ in diameter in the left midzone. Four cases had a diffuse haze that made recognition of the lung parenchyma difficult. Fine calcification was also seen in two cases; one

Table 5 Radiological findings in chest radiographs of rice millers and controls

\begin{tabular}{|c|c|c|c|c|}
\hline & \multicolumn{2}{|c|}{ Rice millers } & \multicolumn{2}{|c|}{ Controls } \\
\hline & No & $\%$ & No & $\%$ \\
\hline $\begin{array}{l}\text { Nodular opacities with/without } \\
\text { reticulation }\end{array}$ & 18 & $14 \cdot 8^{*}$ & 0 & $0 \cdot 0^{*}$ \\
\hline $\begin{array}{l}\text { Increased reticulation (without } \\
\text { opacities) }\end{array}$ & 1 & $0 \cdot 8$ & 0 & $0 \cdot 0$ \\
\hline $\begin{array}{l}\text { Fibrotic and calcified opacities of } \\
\text { old tuberculosis }\end{array}$ & 1 & $0 \cdot 8$ & 2 & $4 \cdot 8$ \\
\hline Generalised haze & 4 & $3 \cdot 3$ & 0 & 0.0 \\
\hline Other abnormalities & 1 & 0.8 & 0 & 0.0 \\
\hline No abnormalities & 101 & $82 \cdot 8$ & 40 & $95 \cdot 2$ \\
\hline
\end{tabular}

${ }^{*}$ Significant difference, $z=2.66, p<0.05$.

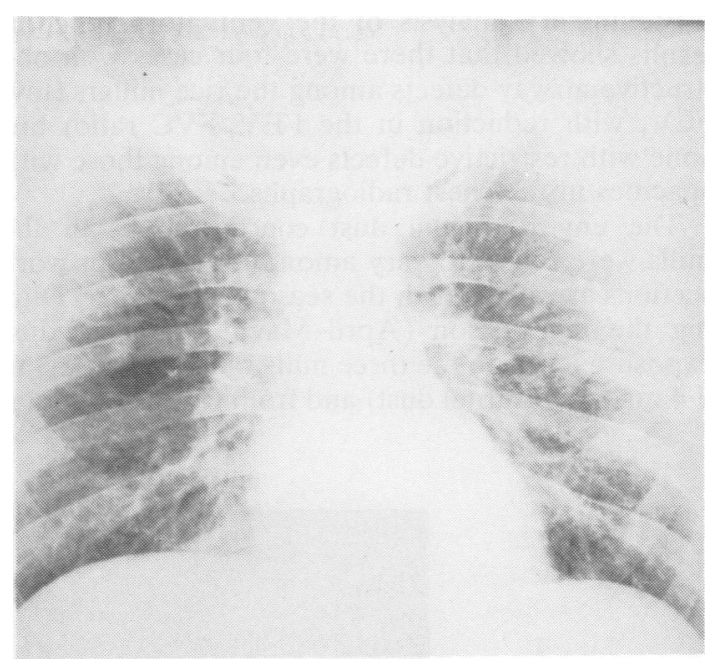

Fig 2 Chest radiograph of a rice miller, showing reticular changes and fine nodulation in lower and midzones of both lungs. There is also a bulla in right midzone.

further case had cystic changes in the right midzone and another had an emphysematous bulla in the right midzone. Apical changes probably due to pulmonary tuberculosis were found in one rice miller and two controls. One rice miller had a dilated main pulmonary artery with pulmonary plethora, suggestive of a small left to right shunt.

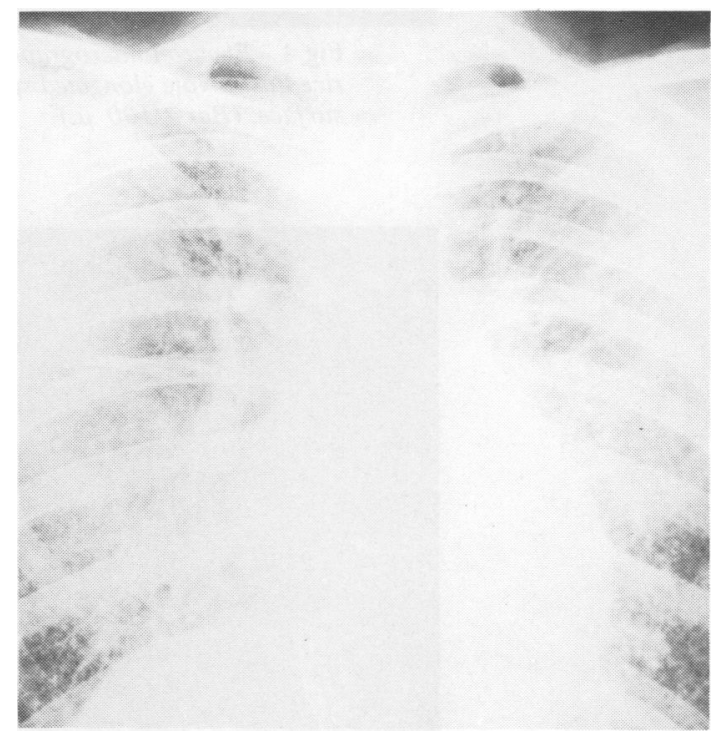

Fig 3 Chest radiograph of another rice miller, showing extensive reticulation and nodulation predominantly in lower and midzones. There is also thickening of the right transverse fissure. 
Preliminary analysis of the ventilatory function results showed that there were four cases with obstructive airway defects among the rice millers (low $\mathrm{FEV}_{1}$ with reduction in the $\mathrm{FEV}, \mathrm{FVC}$ ratio) but none with restrictive defects even among those with opacities in the chest radiographs.

The environmental dust concentrations in the mills were found to vary among the different work sections as well as with the season of the year. During the low season (April-May), the mean dust exposure levels in the three mills ranged from 2.3 to $5.4 \mathrm{mg} / \mathrm{m}^{3}$ (for total dust) and from 0.5 to $1.2 \mathrm{mg} / \mathrm{m}^{3}$

(for respirable dust). In the peak season (around November) the corresponding dust levels were found to have increased by as much as tenfold. It should be noted that there are currently no threshold limit values (TVLs) for rice husk dust.

\section{Discussion}

Findings from the present study have shown significant associations of various clinical signs and symptoms and haematological and radiological changes, with occupational exposure to rice husk

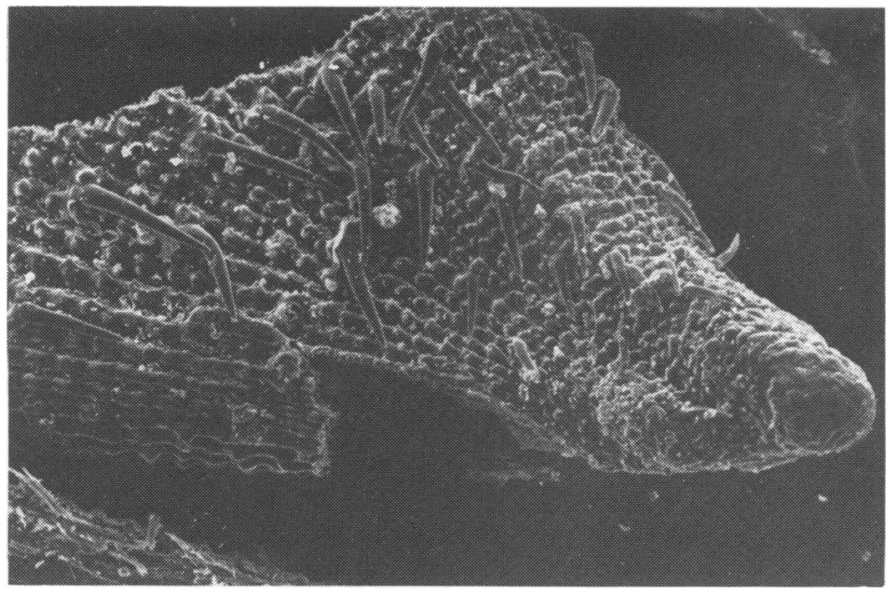

Fig 4 Electron micrograph showing a fragmented piece of rice husk. Note elongated spikes projecting from husk surface. $($ Bar $=100 \mu$.)

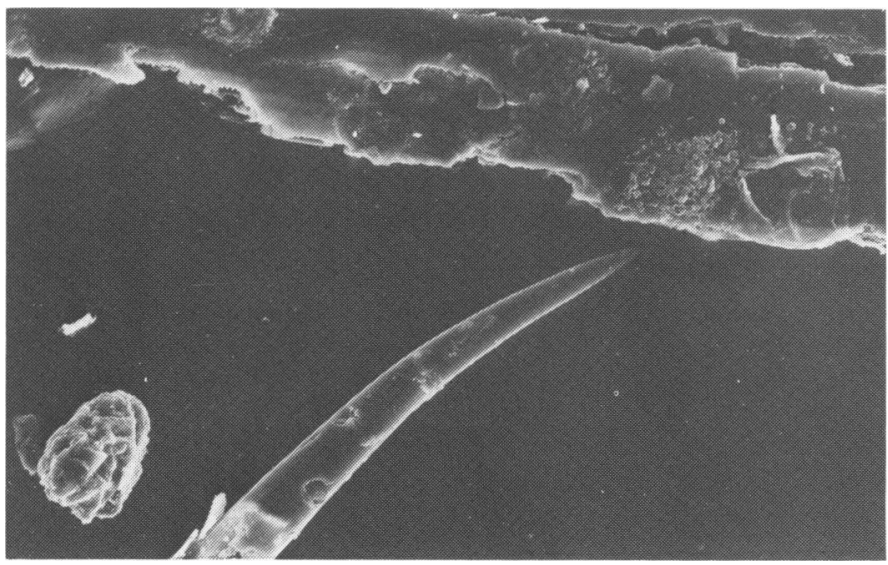

Fig 5 Electron micrograph showing one of the elongated spikes detached from rice husk surface. $($ Bar $=100 \mu$.) 
dust. The clinical and haematological findings suggest that the harmful effects may be linked to both non-specific irritation and allergic responses to rice husk dust. Under the electron microscope, the rice husk is shown to be covered with small needlelike hairs that project outwards as sharp, elongated spines (figs 4 and 5). These spikes are about 200$300 \mu$ in length, and about $30-40 \mu$ in diameter at the base, tapering into sharp ends. The structure of these spikes suggests that they may be responsible for the irritant effects of the rice husk dust exposure, which manifest acutely as irritant cough with or without phlegm, keratoconjunctival irritation, and pruritus. The end results of such non-specific irritation are seen in the corneal scars, chronic conjunctival inflammation, and pterygium formation.

The nasal catarrh, respiratory difficulties such as tightness of chest, and eosinophilia are, however, probably allergic responses, either to a protein constituent of the rice husk or to some microbiological contaminant. Occupational asthma is known to occur in rice workers so that the cases of bronchial asthma seen in the present study may be associated with an allergic aetiology.

Possibly the most striking finding in the current study is the demonstration of chest opacities on radiological examination. The predominant pattern was of fine nodulation and increased reticulation, mainly in the lower and midzones of the lungs, with diffuse haze in some cases. Rice husk has been known to have a high silica content, which has been used for its abrasive action as detergents, dyes, and even as cleansing agents for jet engines. ${ }^{34}$ The nodular shadows may thus represent the early stages of silicosis, although the distribution appears uncharacteristic of classical silicosis. On the other hand, extrinsic allergic alveolitis may also produce these radiological features, although there were no complaints of fevers or pains in the limbs in the rice mill workers. No lung biopsy was performed to identify the pathological features.

It seems that a distinctive clinical syndrome may be associated with exposure to rice husk dust at work for which we propose the term "rice millers' syndrome." Both non-specific irritant and allergic responses seem to be involved, manifesting acutely as irritation of the eyes, skin, and upper respiratory tract in some cases, as well as allergic nasal catarrh, respiratory difficulty, and eosinophilia in others. Chronic irritant effects are seen predominantly in the eyes, whereas cases of occupational asthma are probably found in hypersensitive individuals. Radiological opacities in the chest may either represent the early stage of silicosis or extrinsic allergic alveolitis.

We express our sincere thanks to all those who have helped to make this study possible, in particular the management and workers of the rice mills (National Rice Authority), the heads and staff of the Department of Social and Preventive Medicine and Department of Environmental Sciences, and the director general and staff of the Factories and Machinery Department. The study was supported by a grant from the China Medical Board.

\section{References}

' World Health Organisation. Recommended health-based occupational exposure limits for selected vegetable dusts. (Technical report series No 684.) Geneva: WHO, 1983.

2 Wong PL. Keratitis nummularis among rice cultivators in North Malaya. Med J Malaysia 1968;22:313-22.

${ }^{3}$ Aten A, Gaunce AD, Luther RR. Equipment for the processing of rice. (Food and Agricultural Organisation development paper No 27.) Rome: FAO, 1953.

${ }^{4}$ Standards and Industrial Research Institute of Malaysia. Evaluation of rice-husk as a cleaning agent for turbo jet engines. Berita SIRIM 1983;8:2. 